доктор философии по экономике, доцент Азербайджанского государственного экономического университета

Фейзуллаев Мушфиг Ахад оглы

кандидат экономических наук, доцент, доцент кафедры менеджмента и бизнеса Сургутского государственного университета

\section{ПРОБЛЕМЫ ВЗАИМООТНОШЕНИЙ ЧЛЕНОВ КОЛЛЕКТИВА В УСЛОВИЯХ ПРИМЕНЕНИЯ СИСТЕМНОГО ПОДХОДА К УПРАВЛЕНИЮ}

\begin{abstract}
Аннотация:
Статья посвящена проблемам взаимодействия членов коллектива при выполнении функциональных обязанностей в рамках системного подхода к управлению предприятием. Проанализированы основные составляющие взаимоотношений внутри коллектива, формы общения, эффективность данного процесса и недостатки. Выявленные недостатки предлагается устранять посредством разработанных авторами мер, нацеленных на решение конфликтных ситуаций. Сделан вывод о важности системного управления предприятием посредством формирования коллегиальных органов, борьбы с авторитаризмом и агрессивными методами управления.
\end{abstract}

Ключевые слова:

системный подход к управлению, эффективность, коллегиальное управление, психология общения, конфликт, авторитаризм.
D.Phil. in Economics Assistant Professor, Azerbaijan State University of Economics

Feyzullaev Mushfig Akhad

PhD in Economics, Assistant Professor, Management and Business Department, Surgut State University

\section{RELATIONSHIP PROBLEMS BETWEEN TEAM MEMBERS IN TERMS OF APPLICATION OF SYSTEM APPROACH TO MANAGEMENT}

Summary:

The article is devoted to the problems of interaction between team members in performing functional responsibilities within a system approach to enterprise management. The paper analyzes the main components of the relationship within the team, forms of communication, the efficiency and disadvantages of this process. It is provided to remedy the identified deficiencies through the developed by authors measures aimed at resolving conflict situations. The main conclusions of the article are the priority system of enterprise management by means of the formation of collegial bodies, fight against authoritarianism, aggressive methods of control.

Keywords: system approach to management, efficiency, collegial management, psychology of communication, conflict, authoritarianism.

Ключевой составляющей успешности бизнеса является формирование команды единомышленников, мыслящих и действующих в одном направлении. Однако, какие методы бы ни применялись, организовать такую команду в идеальной форме не представляется возможным. Основными причинами разногласий по тем или иным вопросам выступают различные их понимание, видение решений, способы достижения эффективности и т. д. Успех в выполнении конкретной задачи зависит от компетентности ее исполнителей в вопросах и методах ее решения. Многие люди не понимают сути вопроса не потому, что не имеют соответствующего образования, но потому, что данные вопросы не входят в круг их понятий, ранее они не сталкивались с такими задачами и не имеют соответствующего опыта.

В свое время многие авторы проводили анализ межличностных отношений. Вопросы общения, ведения переговорного процесса, различные аспекты конфлликных ситуаций и другие психологические особенности в деловой среде изучены и доработаны такими авторами, как: Л.К. Аверченко, В.В. Авдеев, В.И. Андреев, Г.М. Андреева, А.А. Бодалев, Х. Вейсбах, Е.И. Голохова, Ю.М. Жуков, Д. Карнеги, Ю.С. Крижанская, А.А. Леонтьев, Б.Ф. Ломов, У. Мастенбрук, М.А. Робер, С.Н. Тидор, Р. Фишер, Р. Фрюлинг, В.М. Шерель и др.

Системный подход как фактор эффективности процесса управления

Системный подход - это подход, при котором любой объект рассматривается как совокупность взаимосвязанных элементов, имеющая вход, выход, связь с внешней средой и обратную связь. Одним из аспектов системного подхода является системно-целевой аспект, означающий необходимость научного определения целей и подцелей системы, их взаимной увязки между собой. Мыслить системно - значить думать, видеть, управлять проблемой в неразрывной связи с конкретной целью, конечной целью компании. Результат каждого процесса должен дать некоторый эффрект системе показателей компании, которые в свою очередь приведут к совокупной эффективности - достижению единой цели предприятия. Предприятие, как часть экономической 
системы, формирует базу программы социально-экономического развития страны. Достижение стратегической цели компанией - залог успеха программы развития государства.

Система ценностей компании включает материальные, технические, трудовые, технологические, информационные ресурсы, стратегию, качество, эффективность и мнение потребителя. Именно ценности упорядочивают людей и побуждают их действовать сообща, в рамках общих интересов [1, с. 78]. Поэтому выбор сильной системы ценностей, учитывающей интересы всех сторон производственного процесса: собственников, трудового коллектива, потребителей, пользователей - может стать началом системного управления компании. Главной ценностью системно развивающейся компании должно выступать формирование команды управленцев, единомышленников, работающих в направлении достижения стратегической цели фирмы.

Сущность системного подхода к управлению заключается в том, что управляющие (топменеджеры) видят свои конкретные задачи частью системной цели предприятия в целом, если они понимают цель системы и свою роль в ней. Это особенно важно для собственника и главного управленца, потому что системный подход стимулирует их поддерживать необходимое равновесие между потребностями отдельных структурных единиц, департаментов, служб и целями всего предприятия. Руководитель должен думать об информационных потоках, как о входящих, так и выходящих из системы, а также акцентировать внимание на работе по формированию у работников системного мышления.

Посредством аналитических исследований системного подхода управляющий может установить причины принятия неэффективных решений. Также данный подход через системное мышление помогает повысить качество и эффективность процессов планирования, организации и контроля.

С учетом вышеизложенного можно констатировать, что системный подход представляет собой комплексную оценку финансово-хозяйственной деятельности предприятия. Он позволяет повысить качественные характеристики процесса управления на всех уровнях руководства, таким образом предоставляя собственнику возможность анализировать конкретные ситуации в пределах отдельно взятой системы с выявлением характера проблем входа, организации процесса производства и выхода [2, р. 6488]. Системный подход обеспечивает эффективное формирование процесса принятия решений, начиная с низового и заканчивая высшим уровнем системы управления предприятием.

Ведущее место при формировании системы управления занимает организация совместной работы коллектива. Б. Честер в своей книге «Функции руководителя. Власть, стимулы и ценности в организации» пишет: «Когда люди собираются вместе и официально принимают решение объединить свои усилия для достижения общих целей, они создают организацию» [3, с. 125]. Т. е. создание организации подразумевает достижение общих целей, тем самым каждый человек становится частью системы.

Деловые отношения и взаимодействия в рамках системного подхода к управлению

Формирование и развитие коллектива происходят на фоне делового общения между его участниками. «Деловое общение - это процесс взаимосвязи и взаимодействия, в котором происходит обмен деятельностью, информацией и опытом, предполагающий достижение определенного результата, решение конкретной проблемы или реализацию определенной цели» $[4$, с. 58]. Деловое общение отличается от обычного тем, что в его процессе ставятся цель и конкретные задачи, которые необходимо решить. Именно цель делового совещания на предприятии является важной составляющей достижения взаимопонимания его участников.

Результат коллективного труда должен удовлетворить пожелания и устремления всех участников производственного процесса. На наш взгляд, отличие системного подхода заключается в том, что участники должны направить свою энергию и силу на достижение общей цели, при этом признавая свои просчеты по тем или иным стратегическим вопросам. Однако часто случаются ситуации, когда целью очередного совещания ставится не решение важного вопроса, а подчеркивание руководителем правоты, престижа и донесение нижестоящим, что вопрос уже решен и дальнейшее его обсуждение недопустимо. Это противоречит основам коллегиального управления и, соответственно, целям системного подхода к управлению.

На принятие решений, в том числе неверных, сильное влияние оказывают такие факторы, как плохое настроение, болезнь человека, антипатия к собеседнику, неприятные впечатления, самолюбие и т. д. Поэтому если исход беседы ясен, то не имеет смысла ее продолжать, лучше еще раз вернуться к решению данной проблемы в составе более расширенной комиссии. Упорство и настырность в принятии тех или иных важных решений может стоить сотруднику работы, даже несмотря на то, что при этом он действует в рамках системно-целевого аспекта системного подхода к управлению ради достижения общей цели компании.

При несовпадении корпоративных интересов компании и личных интересов участников достижение общей цели не представляется возможным. Именно по этой причине коллегиальное 
управление можно рассмотреть в качестве единственно эффрективного механизма принятия управленческих решений в конфрликтных ситуациях.

Достижение единой цели во многом зависит от сформированности коллектива единомышленников, заинтересованных в конечном продукте. Распределительный процесс, организованный на предприятии, оказывает влияние на удовлетворенность работников посредством: уровня заработной платы, занимаемой должности, степени значимости работника и уважения к нему.

На психологические характеристики работника оказывают влияние отношения как на работе, так и в семье. Отношения в семье как внешний фактор, опосредованно воздействующий на производственный процесс, тоже зависят от сложившейся ситуации на предприятии. Психологическая атмосфера на производстве, где сотрудник проводит не менее 8-10 часов в день, может оказать как положительное, так и отрицательное влияние на его настроение, здоровье и т. д. Конечно, одним из важных фракторов удовлетворенности человека своим трудом является денежное вознаграждение. Если размер денежного вознаграждения и «самооценка» работника совпадают, то такой работник будет настроен на достижение конечного результата.

Второй фактор самоотдачи работника - это занимаемая должность, потенциальный карьерный рост, возможность самовыражения и включение его в список топ-менеджеров. Работнику, как правило, хочется быть ближе к руководству, участвовать в важных совещаниях, быть в курсе всех изменений. Однако в данном случае ему придется показать свои конкурентные преимущества относительно других работников. В условиях психологического напряжения, несовместимости с коллегами борьба за «место под солнцем» часто приводит к межличностным разборкам, тогда системность в достижении общих целей компании ставится на второй план. При решении важных вопросов противоборствующие стороны стараются обосновать собственную правоту, таким образом доказывая свою важность и победу над противником, что опять же приводит к уходу от системного подхода к решению вопроса. Данный вариант называется «спор для одержания победы», когда стороны ведут дискуссию для самоутверждения и при этом пользуются всеми возможными средствами и приемами ее достижения. Межличностные конфликты - это один из самых распространенных типов конфликтов на предприятиях.

Немаловажным фактором заинтересованности работника в достижении конечного результата является его значимость для предприятия. «Неформальный лидер», «старожил», «мозг компании» - носители таких имен всегда пользуются уважением в коллективе. Чтобы стать уважаемыми, людям необходимо показать свои способности, умения, знания, компетенции, опыт при выполнении поставленных задач и решении значимых для компании вопросов. Но до этого работнику предстоит пройти долгий путь, возможно даже преодолевая унижения, чувства досады, недовольства, сопротивляясь обстоятельствам. В эти моменты инстинкт самосохранения может привести к появлению конфликтогенов: проявлению агрессивности, эгоизма, стремления к превосходству. Все это направлено на решение психологических проблем или достижение поставленной цели. Ради повышения собственного статуса работник использует свои волевые качества, что может быть эффективным способом достижения цели, если он обладает определенной властью, его решение совпадает с целями компании и он может настаивать на нем. Такой подход возможен, если работник имеет достаточный авторитет. Предполагается, что его авторитет упрочится, если результат окажется положительным.

Заслужить уважение руководства и коллег можно при условии соблюдения этических норм поведения, общения, выбора корректного тона разговора, хладнокровного решения проблем, отстаивания своего мнения за счет точных выводов и умозаключений без споров и ухода от конфлликтных ситуаций. С уважением в коллективе относятся к руководителям, имеющим огромный опыт работы, при этом не отличающимся эгоизмом и высокомерием.

Работнику важно знать, как он выглядит в глазах своих коллег, трудового коллектива. Т. е. каждый хочет иметь безупречную репутацию и привлекательный имидж. Профессиональный имидж не должен стать самоцелью, но его формирование имеет большое значение, составляя профессиональную и личностную характеристику человека.

Управленец, чтобы формировать свой имидж, должен обладать как природными качествами, так и приобретенными в процессе образования и воспитания. Он должен быть коммуникабельным, способным понять оппонента, иметь сформированные навыки межличностного общения, нравственные ценности. Нравственный человек осознает необходимость жить по моральным заповедям, выверенным человеческим опытом, тогда как безнравственный всегда находится в плену у собственных страстей, его кредо - вседозволенность [5, с. 243].

Человек, занимающий руководящую должность, прежде всего должен быть компетентным, знать, как выполнить свою работу максимально эффективно. К сожалению, в современных организациях 90 \% менеджеров занимаются не своим делом. Причиной этого выступает случайный характер трудоустройства, точнее говоря, по родственным связям или стечению обстоятельств. Заняв такую нишу, новоиспеченный менеджер считает себя избранным, наделенным качествами руководителя соответствующей службы. 
Авторитаризм - огромная проблема российской системы управления, так как он подразумевает безапелляционность суждений, категоричность в принятии решений. С учетом того, что системный подход к управлению включает стратегическую модель поведения, формирование правил достижения конкретной цели, полагаем, авторитарное поведение может нарушить целостность данной модели. Д. Карнеги в своей книге «Как завоевывать друзей и оказывать влияние на людей» писал: «Сделайте так, чтобы собеседник почувствовал свою важность, значительность, и сделайте это искренне»; «Покажите, что Вы уважаете точку зрения собеседника. Никогда не говорите ему, что он не прав» [6]. Данные высказывания не свойственны человеку с авторитарным мышлением управления. Завышенная самооценка, переоценка собственного видения, любование собственной харизмой позволяют таким руководителям ставить себя выше других. Цель таких управленцев - достижение личного эффректа, иногда с помощью агрессивных подходов управления, посредством реорганизационных мероприятий, противоречащих постулатам системного управления и системной цели компании.

Соответственно, можно отметить, что каждая организация представляет собой систему, в рамках которой происходит превращение набора вкладываемых в производство ресурсов - затрат (материальных, технических, трудовых) в товары, работы и услуги. Главной движущей силой данной системы являются ее работники. Сформированные конструктивные межличностные взаимоотношения между ними - залог успеха всех начинаний коллектива в условиях системного управления предприятием.

\section{Ссылки:}

1. Бланшар К., О’Коннор М. Ценностное управление. Минск, 2003.

2. Feizullaev M.A.O., Javadov R.J.O. A new look at enterprise system management // International Business Management. 2016. Vol. 10, iss. 28. P. 6488-6490.

3. Честер Б. Функции руководителя. Власть, стимулы и ценности в организации / пер. с англ. В. Кошкина. Челябинск, 2009.

4. Бороздина Г.В. Психология делового общения : учебник. М., 2008. 293 с.

5. Там же. С. 243

6. Карнеги Д. Как завоевывать друзей и оказывать влияние на людей. М., 1989.

\section{References:}

Blanchard, K \& O'Connor, M 2003, Managing by values, Minsk, (in Russian).

Borozdina, GV 2008, Psychology of business communication, textbook. Moscow, 293 p., (in Russian).

Carnegie, D 1989, How to win friends \& influence people, (in Russian).

Chester, B \& Koshkina, V (transl.) 2009, The functions of the head. Power, incentives and values of the organization, Chelyabinsk, (in Russian).

Feizullaev, MAO \& Javadov, RJO 2016, 'A new look at enterprise system management', International Business Management, vol. 10 , iss. 28 , pp. 6488-6490. 